\title{
Supply Chain Management in Food Chains: Improving Performance by Reducing Uncertainty
}

\author{
J. G. A. J. VAN DER VORST, A. J. M. BEULENS, W. DE WIT and \\ P. VAN BEEK
}

Wageningen Agricultural University, Hollandseweg 1, 6706 KN Wageningen, The Netherlands

\begin{abstract}
This paper investigates the impact of Supply Chain Management on logistical performance indicators in food supply chains. From a review of quantitative and more qualitative managerial literature, we believe that Supply Chain Management should be concerned with the reduction or even elimination of uncertainties to improve the performance of the chain. The following clusters of sources of uncertainty are identified: order forecast horizon, input data, administrative and decision processes and inherent uncertainties. For each source of uncertainty, several improvement principles are identified. A case study was conducted in a food chain in which a simulation model helped quantify the effects of alternative configurations and operational management concepts. By comparing this simulation study with a pilot study, the model is validated against real data, and organisational consequences are identified. The results of the case study suggest that reduction of uncertainties can improve service levels significantly, although current supply chain configurations restrict possible benefits. The availability of realtime information systems is found to be a requirement for obtaining efficient and effective Supply Chain Management concepts. (C) 1998 IFORS. Published by Elsevier Science Ltd. All rights reserved
\end{abstract}

Key words: Supply chain management, uncertainty, chain simulation model, pilot study, continuous replenishment.

\section{INTRODUCTION}

Recent literature on Supply Chain Management has been stressing the need for collaboration among successive actors, from primary producer to end-consumers, to better satisfy consumer demand at lower costs (see, for example, Scott and Westbrook, 1991; Ellram, 1991; Towill, 1996). Jones and Riley (1985) define Supply Chain Management (SCM) as an integrative approach to dealing with the planning and control of the materials flow from suppliers to endusers. According to Fearne (1996), SCM seeks to break down the barriers which exist between each of the links in the supply chain, in order to achieve higher levels of service and to substantially reduce costs. "It seeks to achieve a relationship of mutual benefit by defining the organisational structures and contractual relationships between buyer and seller, which up until now have been classified as adversarial" (Fearne, 1996). Iyer and Bergen (1997) emphasise Pareto improvement, referring to the situation in which all parties are at least as well off, and one party is better off than before. Stevens (1989) describes a supply chain as a system whose constituent parts include material suppliers, production facilities, distribution services, and customers linked together via the feed forward flow of materials and the feedback flow of information (Fig. 1). SCM does, however, create some additional flows. Reverse logistics, i.e., remanufacturing and product recovery, creates feedback flow of materials (see, for example, Thiery et al., 1995 and Verrijdt, 1997). Sharing inventory or production scheduling information, on the other hand, creates feed forward flow of information. Furthermore, note that an individual business can be a part of many different supply chains at the same time, i.e., it functions as a focal organisation within a network.

Paper presented to the Seventh International Special Conference of IFORS: 'Information Systems in Logistics and Transportation', Gothenburg, Sweden, 16-18 June 1997.

Corresponding author.Tel.: +31317483644; Fax: +31317 485454; E-mail: Jack.vanderVorst@alg.bk.wau.nl 


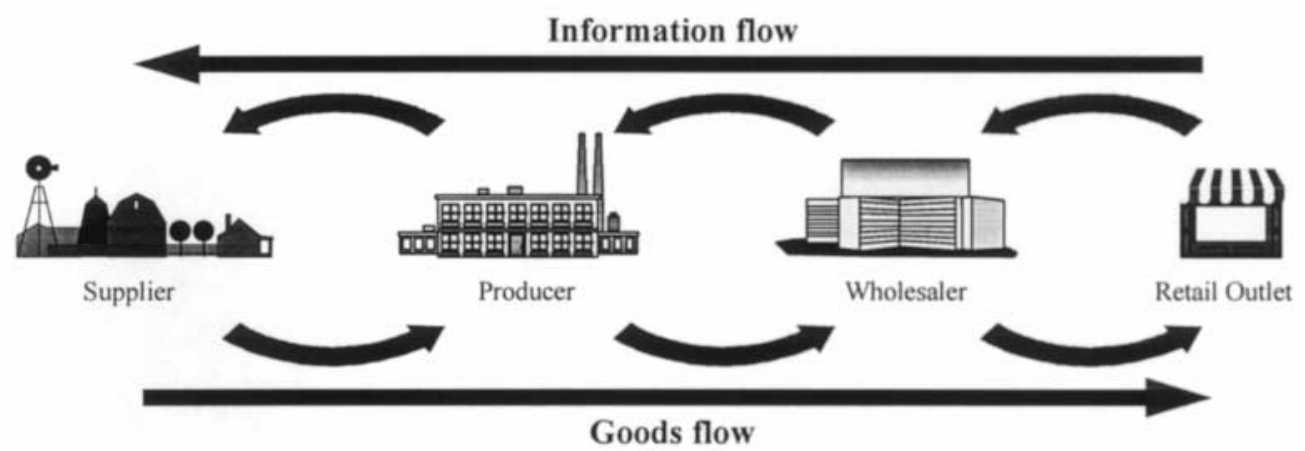

Fig. 1. Reference model for a supply chain.

The traditional way of coping with uncertainties, caused for example, by quality variation, supplier unreliability and unpredictable customer demand in each stage of the supply chain, has been to build inventories or to provide excess capacity. This is now regarded as costly and inefficient. One of the key attributes of a successful player in today's highly competitive marketplace seems to be the ability to respond rapidly to end-consumer demand (Stalk and Hout, 1990). Hence, competition between individual organisations is being replaced by competition between supply chains. Supply Chain Management should recognise end-customer service level requirements, define where to position inventories along the supply chain and how much to stock at each point, and it should develop the appropriate policies and procedures for managing the supply chain as a single entity (Jones and Riley, 1985). We believe that in order to create lean and responsive supply chains, uncertainties which restrict operational performance on the chain level should be systematically and jointly tackled by all stages in the supply chain.

The objectives of this paper are to link a managerial view of supply chain management to a quantitative approach and to provide insight into sources of uncertainty which restrict supply chain performance. From a review of quantitative and more qualitative, managerial literature, four clusters of sources of uncertainty are identified: order forecast horizon, input data, administrative and decision processes, and inherent uncertainties. For each source of uncertainty, several principles for improving operational performance are identified. In the context of a case study, we have quantified the impact of several scenarios for a food supply chain by building a simulation model consisting of all relevant logistical processes in each stage of the supply chain. The research was extended with a pilot study, which allows us to validate the model against real data and also provides an insight into the organisational consequences of formulated scenarios.

\section{SUPPLY CHAIN MANAGEMENT AND UNCERTAINTY}

The traditional way of communicating demand for products or services across a supply chain as depicted in Fig. 1 is the purchase order. Usually, a customer of each stage keeps his internal data hidden from his suppliers, regarding, for example, sales patterns, stock levels, stock rules, and planned deliveries. McGuffog (1997) states that even when customer demand is stable, institutional factors (including structures and timetables, computer systems, capacities of machines, depots or vehicles, etc.) or random factors tend to make the demand expressed at each subsequent stage upstream in the supply chain more cyclical and extreme in variation. This phenomenon, in which orders to the supplier tend to have larger variance than sales to the buyer (i.e., demand distortion) and the distortion propagates upstream in an amplified form (i.e., variance amplification), is called the Forrester effect (Towill, 1996) or the bullwhip effect (Lee et al., 1997). This effect has serious cost implications. For instance, the manufacturer incurs excess raw materials costs or material shortages due to poor product forecasting; additional manufacturing expenses created by excess capacity, inefficient utilisation and overtime; and mostly excess warehousing expenses due to high stock levels (Towill, 1996; Lee et al., 1997). Kurt Salmon Associates (1993, p. 83) suggest that these activities can result in excess costs of $12.5 \%$ to $25 \%$. Forrester (1961) showed that the effect is a consequence of industrial dynamics or time varying behaviours of industrial organisations and the lack of correct feedback control 
systems. Lee et al. (1997) examined the bullwhip effect in several case studies and identified four major causes: demand signal processing (if demand increases, firms order more in anticipation of further increases, thereby communicating an artificially high level of demand which is worsened by long lead times); order batching (due to fixed costs at one location); price variations (which encourage bulk orders); and shortage gaming (there is, or might be, a shortage so a firm exaggerates orders in the hope of receiving a larger share of available items). Thus, the effect may be caused by reactions to uncertainties in demand or supply and the complexity and structure of current decision processes. But what are sources of uncertainty and how can uncertainty be eliminated or reduced?

In the literature, several measures are discussed to improve supply chain performance. SCM is generally associated with reduction of all time delays in goods and information flows and elimination of as many non-added-value operations as possible. Information flows are emphatically included, because, as Braithway (1993) puts it, spending millions of dollars to reduce the manufacturing cycle time by one day, while leaving untouched the two to three-week ordering time which can dominate total turnaround time, is futile. Stalk and Hout (1990) found that work-in-process and stock levels move up and down with the length of the order cycle time, and the way forward is to attack lead times as a high priority, knowing that all other major performance indicators will follow. The idea is that if forecast horizons are shortened, forecast errors will also decrease. Hence, the control problem becomes more manageable. As a rule of thumb, Stalk and Hout (1990) found that reducing the lead time by $50 \%$ will reduce the forecast error by 50\%. Furthermore, Towill (1996) concludes that supply chain processes can be greatly improved by simplifying decision making procedures. Other authors look at information available to supply chain partners and the speed at which it is available, as it has the potential to radically reduce inventories and increase customer service (see, for example, Moinzadeh and Aggarwal, 1996; Cachon and Fisher, 1997; Bourland et al., 1996; and Kreuwels, 1994). Numerous authors of operations research literature deal with co-ordination of supply chains, but usually each model only takes a few variables into account. As Silver (1991) states: "Most models only consider inventory and backholding costs, forgetting all about the cost of order processing, handling and transportation. Furthermore, these models forget interaction effects since they are not concerned with, for example, utilisation degrees of trucks, which influence delivery quantities." In this article, we will try to integrate a range of improvement options by focusing on sources of uncertainty within supply chain decision making. Deduced from literature and practical experience, we distinguish four main clusters of sources of uncertainty which restrict operational performance: order forecast horizon, input data, administrative and decision processes, and inherent uncertainties (van der Vorst et al., 1998).

\section{SOURCES OF UNCERTAINTY}

The first and main cluster of sources of uncertainty is the total order forecast horizon, where we refer to the time period from placement of an order (order 1) to the receipt of goods of the following order (order 2; see Fig. 2). When generating order 1, all sales (and waste) estimates within this total time frame need to be taken into account. We distinguish two relevant elements within the total order forecast horizon: order lead time and order sales period. The order lead time is the time that elapses from the moment an order is placed to the point in time when ordered goods are received. In this time period, we consider five elements: (1) the information lead time, i.e., the time needed for the order to be received and processed by the supplier; (2) the administration or decision process time, i.e., the time needed to generate a production plan (in case of production to order), picking lists and distribution schedules; (3) the time needed to produce the products (if applicable); (4) the distribution lead time, i.e., the time needed to pick, load and transport the products; and very important, (5) waiting times between processes. Of course, each one of these aspects could be divided into sub-elements, but that would go beyond the scope of this article. The order sales period represents the time period between two successive deliveries. The order, of which the goods are delivered after the order lead time, should be large enough to suffice for sales during this order sales period. Low delivery frequencies and long order lead times may increase uncertainty leading to high safety stock levels and many non- 


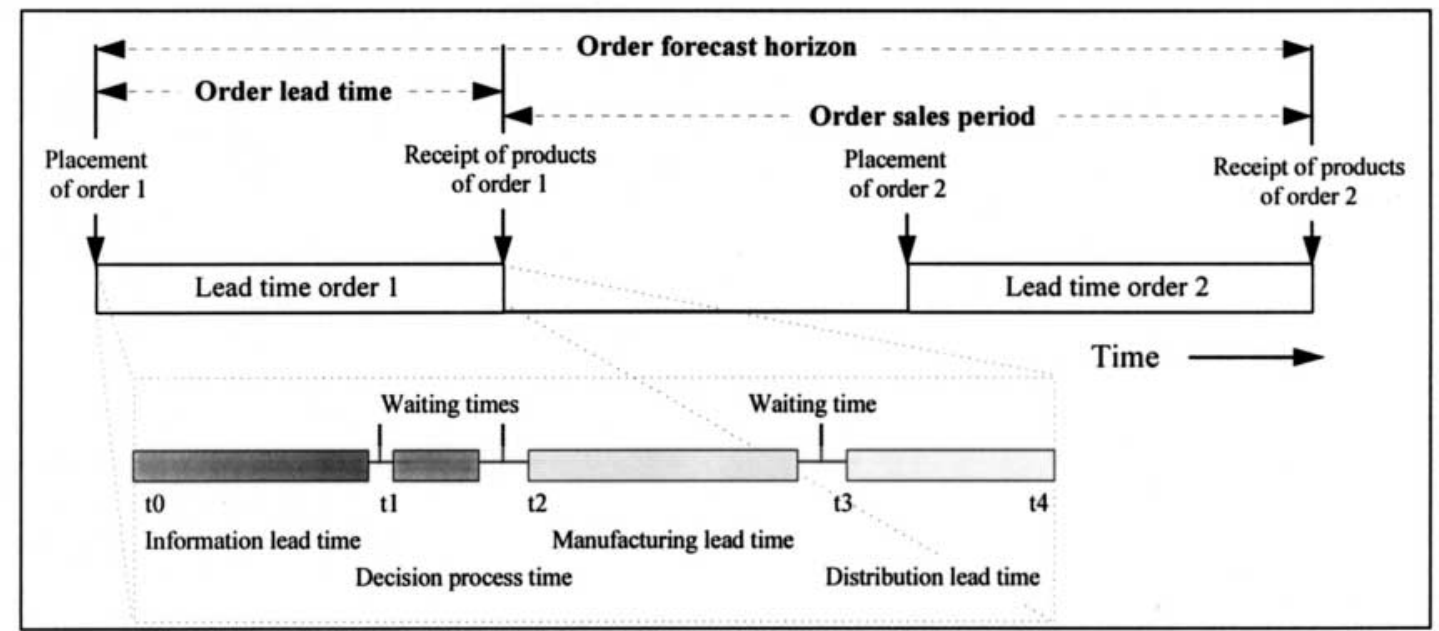

Fig. 2. Time windows in the order cycle.

value-added activities. Reducing the total order forecast horizon, the sum of the order lead time and order sales period, has a high potential for improving supply chain performance.

The second cluster of sources of uncertainty is related to input data available for a decision. The information availability and transparency in the supply chain has the potential to radically reduce costs and increase customer service. van der Duyn Schouten et al. (1994) found that information on the status of upcoming production runs provided by a supplier, who produces on order in fixed production cycles, enables a retailer to reduce inventory costs by up to $30 \%$ (while still satisfying service constraints and requirements). Data timeliness and data applicability are prerequisites when exchanging information. Inventory control systems must be up-to-date and well managed in order to provide current information on stock levels and stock availability (Lewis and Naim, 1995). If they are not, the total time frame of consideration, i.e., the order forecast horizon, becomes even larger. Furthermore, information on consumer demand must be provided in the right format to eliminate translation problems (Beulens, 1992). When a producer receives all sales data of a certain product group, he would like to know how much of each particular product has been sold, so that he can plan his production accordingly. Similarly, a potato supplier of a salad producer has no use for consumer demand data of salads in retailer outlets if he cannot translate them into quantities of potatoes; especially if he is not the only potato supplier to that particular producer. Finally, the specification of data definitions can be a source of uncertainty. Harland (1995) investigated whether the logic of the bullwhip effect also applied to other parts of the information package, such as understanding customer expectations, understanding performance or customer satisfaction/dissatisfaction. Four supply chains in the automotive aftermarket were examined by semi-structured interviews. In this sample of supply chains, evidence was provided of increasing customer dissatisfaction and misperception of performance upstream in the supply chain. On further testing it was found that customer dissatisfaction was significantly positively correlated to misperceptions in performance, but not to misperceptions of requirement, mainly because different measurements were being used by both parties (Harland, 1995).

The third cluster refers to administrative and decision processes, in particular to decision policies and the influence of human behaviour. The application of ordering and production rules with fixed batch sizes, use of local demand and inventory information, and comparison of internal costs with local service provided at fixed points in time, leads to sub-optimisation. Additional uncertainty is created by ignoring or aggregating information in administrative or decision policies. There is a lot of literature on two-echelon models with stochastic consumer demand and order batch sizes (a small sample includes van Beek, 1981; Svoronos and Zipkin, 1988; Axsäter, 1993; Chen and Zheng, 1995; Cachon, 1995). These papers assume retailers may order each period, and can be used to study the relationship between batch size and supply chain performance. They show that decision policies are directly related to operational performance, but pay less attention to the influence of human behaviour. Specific human behaviour in 
decision making processes can result in different outcomes because of cognitive or political influences, among others (think of shortage gaming and forward buying because of price discounts).

The last cluster of sources of uncertainty in (especially food) supply chains is inherent uncertainty in demand, process and supply. Even if you know average consumer demand, there are always variations due to weather changes and changing consumer preferences. Inherent process uncertainty refers to fluctuations in process outcomes and production times due to variable process yield, perishable end-products, machine breakdowns, scrap, etc. Inherent supply uncertainty can be caused by fluctuations in supply performance due to natural variations in quality, seasonal patterns, variable yield, etc. SCM can reduce the effect of inherent uncertainties marginally by increasing the information exchanged up- and downstream in the supply chain and by adapting procedures to it. The main benefits of SCM are obtained in the reduction of the other sources of uncertainty. Therefore, this paper concentrates on these sources, as summarised in Table 1. For each source of uncertainty, the most important principles used to eliminate or reduce the corresponding uncertainty and improve operational performance are also mentioned in Table 1.

Many of the improvement principles have already been discussed in the literature and applauded for their contribution to the improvement of (or part of) supply chain performance, but they have not all been directly correlated with a source of uncertainty. Moreover, the tradeoff of different measures and the combination of several measures have not yet been investigated in detail, nor have all relevant performance indicators been taken into account. The main contribution of this article is a discussion of the integral effects of possible improvement principles in food supply chains, from a modelling perspective as well an organisational perspective. We present a case study of a supply chain for chilled salads, in which we quantify the hypothetical benefits of uncertainty reduction by applying a combination of one or more improvement principles in a simulation model and in real life. The results of the model study are compared with real benefits obtained in the pilot study.

\section{CASE STUDY: A SUPPLY CHAIN FOR CHILLED SALADS}

We have identified a chain reference model for an existing supply chain for chilled salads in the Netherlands which consists of a producer, a retail distribution centre (DC) and approximately 100 retail outlets (Fig. 3). In the current situation the producer supplies the DC with approxi-

Table 1. Sources of uncertainty and some corresponding improvement principles

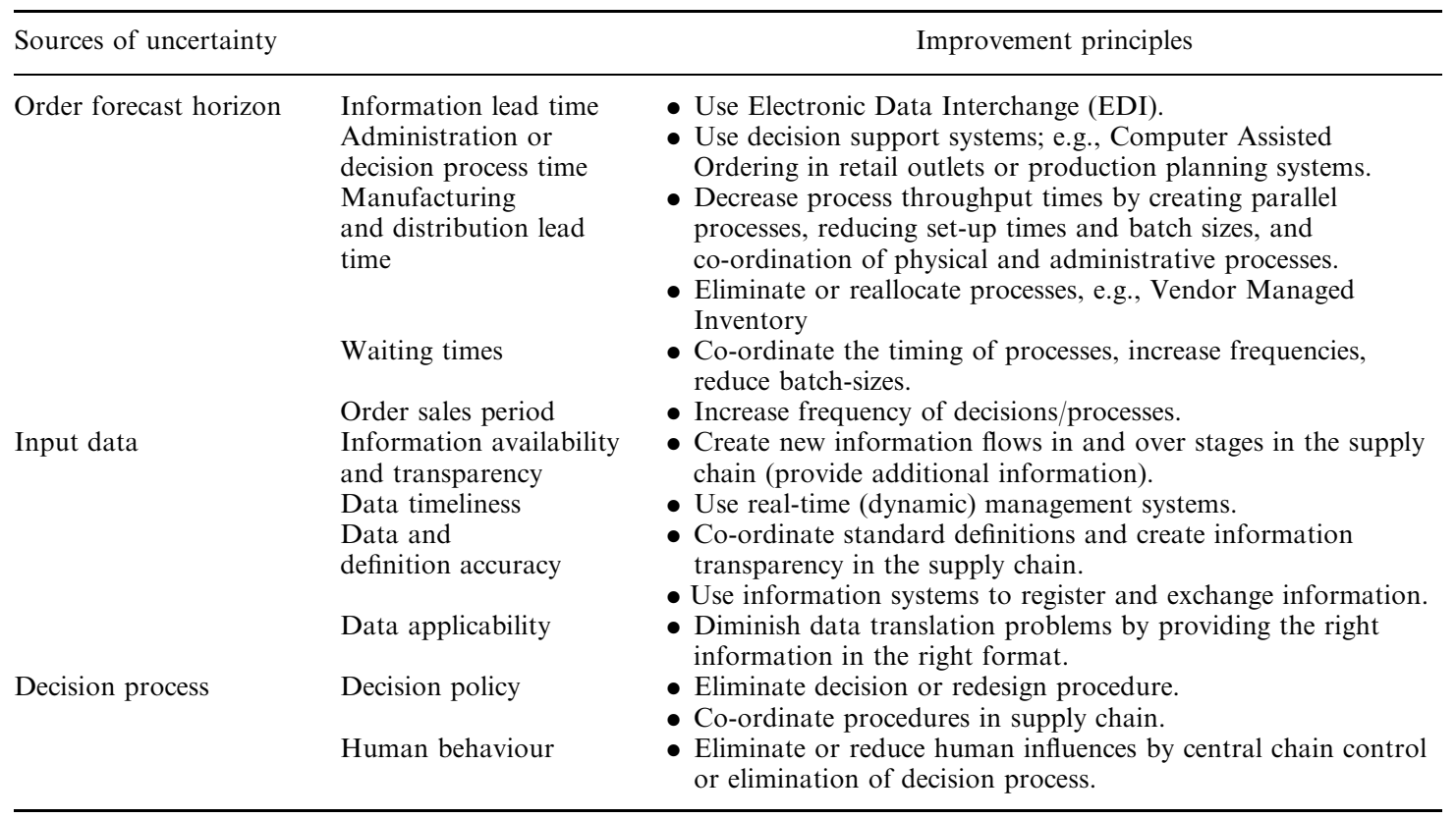




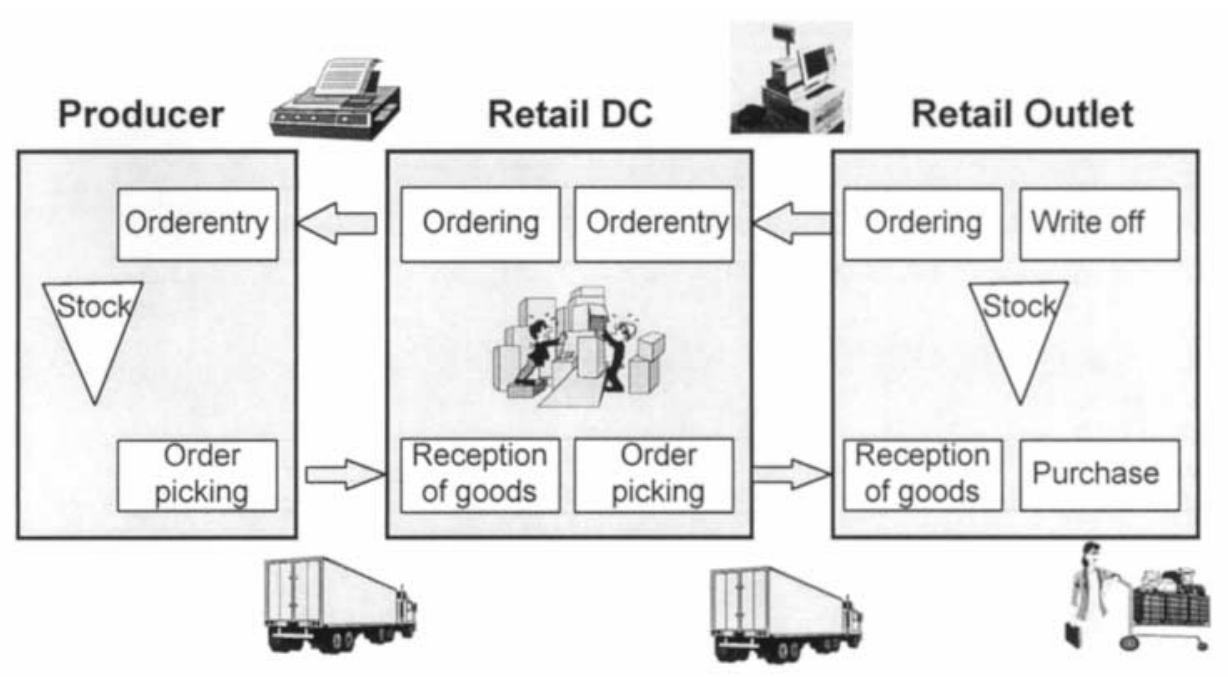

Fig. 3. Supply chain for chilled salads with the relevant processes.

mately 60 different products twice a week, with an order lead time of three days for each delivery. The DC supplies the retail outlets chilled salads, simultaneously with other fresh products, three times a week from stock, with an order lead time of one day according to pre-set delivery schedules. The average inventory in the DC covers 4.0 days of sales and in the outlets 6.8 days of retail sales. The DC order policy is based on actual outlet orders, historical sales patterns and present inventory levels. In outlets, managers try to forecast their sales by looking at the sales figures of previous weeks, but basically order to fill available shelf space (compare with $(R, S, S)$-policy).

All stages of the supply chain experience a great deal of demand uncertainty, mainly caused by long order forecast horizons (6 days for the DC and 3 days for a retailer outlet) and the duration and quality of current administrative and decision processes. Because of intensified competition in this market, which includes many promotional activities, demand uncertainty increased last years. The highly perishable and seasonal nature of the products only further increases uncertainty. Because of the presumed impact of uncertainty on performance, all parties were interested to find out what benefits closer collaboration could bring. Therefore, a research project* was started aimed at understanding the prerequisites and potentials of some of the subconcepts of Efficient Consumer Response (ECR); namely Continuous Replenishment (CRP) and related concepts such as Cross Docking and Computer Assisted Ordering. With CRP the retail DC and retailer outlets' inventory is managed by more frequent and smaller deliveries based on a combination of actual sales and forecasted demand. Because the project focuses on physical distribution, the attention given to the producer at this point is limited to order entry, inventory control and expediting goods to the retailer DC.

The general logistical objective of this chain partnership is the improvement of customer service (reduction of the number of out-of-stocks, fresher products and better assortment) at lower total chain costs (lower inventories, higher sales, fewer write-offs), which should result in higher sales and profits for all chain participants. To measure the effectiveness and efficiency of alternative chain structures, this objective was translated into the following performance indicators per product:

Costs

- Costs related to average stock level at distribution centre and retail outlets.

- Costs related to all relevant processes at all stages in the supply chain.

- Costs of product write-offs and necessary price reductions.

*This research project was partly funded by the Foundation of Agri-Chain Competence as part of the Dutch Efficient Consumer Response project. We would like to acknowledge Coopers \& Lybrand, ATO-DLO and the participating companies for their co-operation in this research project. 
Service

- Number of out-of-stocks at the retail stores.

- Number of missed sales caused by stock-outs.

- Delivery reliability of producer and retail DC.

- Average remaining product freshness.

- Utilisation degrees of transport carriers.

- Product assortment.

Note that, in food chains, product freshness is considered to be a major performance indicator. In the terminology of Hill (1993), it is one of the most important customer order winners.

\subsection{Research methodology}

Our research methodology comprises four phases (Fig. 4). First, via a process flow analysis, objectives and performance indicators of relevant processes are defined. In developing detailed process models, emphasis is placed on analysing current roles and tasks in the supply chain, determining constraints for executing those roles in a chain perspective, and evaluating current (Information Technology) infrastructures and operations management. The relationship between processes is described, including the timing and place of each process (in accordance with the elements of Fig. 2), information required to fulfil the task and task uncertainty. This analysis results in the determination of possible alternative configurations of roles and tasks performed in the supply chain, and the co-operation and integrated planning of these operations within the control configuration established, named scenarios.

The second phase contains three parallel steps. The first is the construction of a simulation model which can be used to quantify each of the performance indicators for relevant processes and evaluate them according to logistical objectives. The detailed process models of the first phase, constitute an ideal starting point for supply chain modelling. The second step is the implementation of one simple scenario in a pilot project to identify organisational consequences and restrictions to the information infrastructure in all stages of the supply chain, and to measure chain performance. The configuration of the pilot study should be based on preliminary results of simulated scenarios. Because of risks and costs involved, it is impossible to test all scenarios in practice. The third step is the definition of a number of relevant scenarios, for which the improvement principles presented in the previous section can be of help.

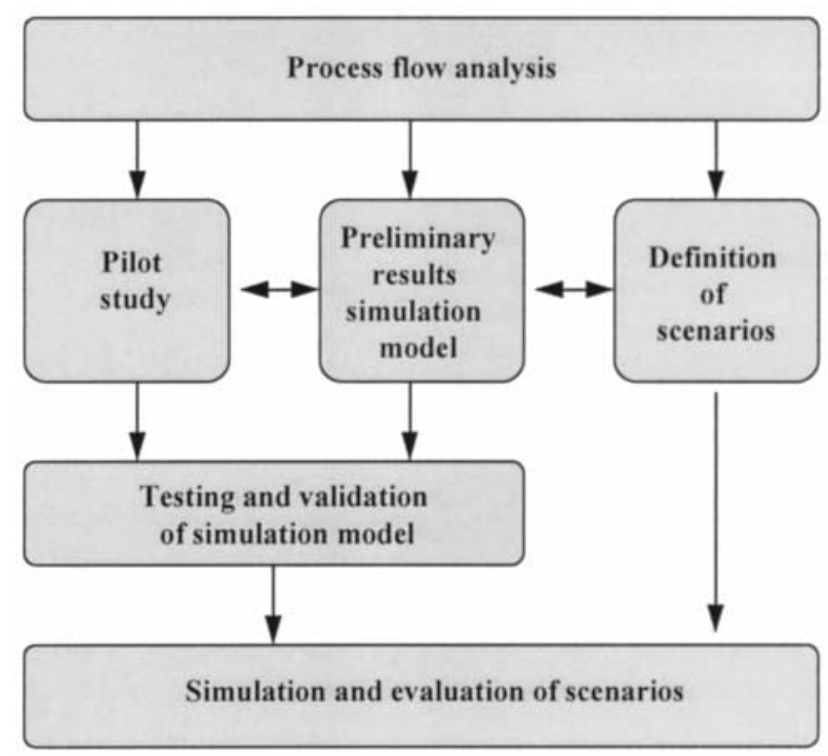

Fig. 4. Research model. 
Table 2. Investigated improvement principles in the supply chain for chilled salads

\begin{tabular}{|c|c|c|}
\hline Management level & Improvement principle & Source of uncertainty \\
\hline \multirow[t]{2}{*}{ Strategic/configuration } & $\begin{array}{l}\text { - Implementation of a Computer Assisted } \\
\text { Ordering (CAO) system in retail outlets, a real- } \\
\text { time inventory system at the retail DC, and EDI } \\
\text { with the producer. }\end{array}$ & $\begin{array}{l}\text { - Data timeliness } \\
\text { - Information lead time } \\
\text { - Decision process time }\end{array}$ \\
\hline & $\begin{array}{l}\text { - Increasing delivery frequency between DC and } \\
\text { producer from } 2 \text { to } 5 \text { times a week and between } \\
\text { DC and outlets from } 3 \text { to } 6 \text { times a week. }\end{array}$ & $\begin{array}{l}\text { - Order sales period } \\
\text { - Data timeliness }\end{array}$ \\
\hline \multirow[t]{3}{*}{$\begin{array}{l}\text { Operational management } \\
\text { and control }\end{array}$} & $\begin{array}{l}\text { - Shortening lead time to one day; altering the } \\
\text { timing of each process. }\end{array}$ & $\begin{array}{l}\text { - Waiting times } \\
\text { - Order lead time }\end{array}$ \\
\hline & $\begin{array}{l}\text { - Both partners agreeing to relevant performance } \\
\text { indicators, including the definitions. }\end{array}$ & - Data accuracy and applicability \\
\hline & $\begin{array}{l}\text { - Simplifying the DC ordering policy; simply } \\
\text { passing on aggregates of the outlets' orders and } \\
\text { current inventory levels. }\end{array}$ & $\begin{array}{l}\text { - Ordering policy } \\
\text { - Human behaviour } \\
\text { - Information availability }\end{array}$ \\
\hline
\end{tabular}

The third phase is the validation of the simulation model based on the results of the pilot study. And finally in the fourth phase, the simulation model is used to evaluate the relevant scenarios, based on pre-defined performance indicators. This phase, together with the findings of the pilot study, results in a recommendation for implementation of one scenario in the supply chain.

\subsection{Analysis}

The process flow analysis resulted in improvement principles and corresponding sources of uncertainty, listed in Table 2. These options can be divided into two levels: strategic management (designing the chain configuration and related information systems) and operational management and control. From the analysis, it is clear that the timing of activities, the infrastructure and information availability are responsible for the greatest part of existing uncertainty. The results of the process flow analysis were used in designing the pilot study.

\subsection{Pilot study}

Based on three factors, i.e., insights obtained from literature on ECR, preliminary simulation results giving indications of what performance improvements to expect, and, finally, the participation of companies, one scenario was chosen for the pilot study, which encompassed the implementation of maximum delivery frequencies from supplier to DC and from DC to retail outlets. The partners were particularly interested in the organisational and infrastructural consequences of this extreme scenario. The pilot project lasted for six weeks and the improvement principles in Table 2 were implemented in two outlets; the only distinction between the two being that one began ordering with a CAO-system (hereafter called the CAO-outlet) in which the system tries to order pro-actively expected sales, and the other continued ordering in the traditional way (traditional outlet). Hence, only at two of the 100 outlets delivery frequencies were increased and lead times shortened. One additional outlet of comparable size was chosen in which no modifications were made (standard outlet). Starting two weeks before the pilot project a lot of detailed information was collected and recorded by participating companies concerning relevant performance indicators for 12 representative products. During the pilot period, realtime inventory control and EDI were simulated (by manually increasing DC inventory levels in the information system some time before the actual arrival of ordered goods, and, respectively, by receiving a fax from the producer indicating to-be-delivered products). For all products, target inventory levels were determined based on peak weekly demand and a percentage of safety 


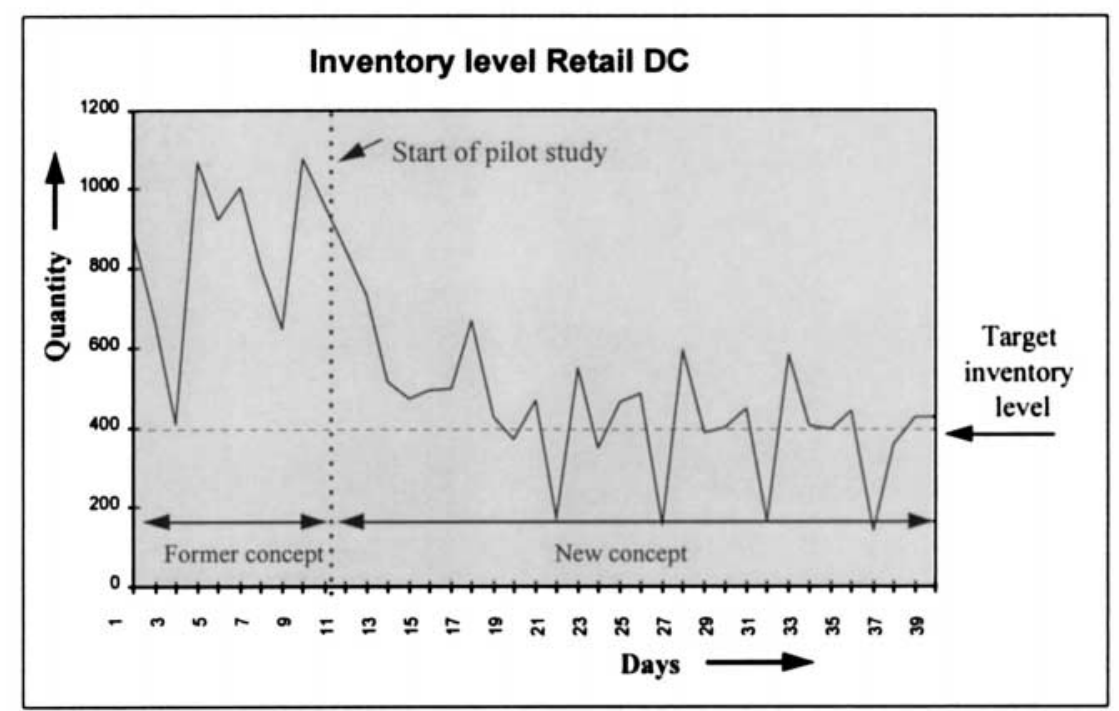

Fig. 5. Inventory levels in the distribution centre during the pilot study.

stock (the sum of targets of the 12 selected products was 400). Figure 5 shows the decrease in inventory levels at the retail DC, mainly caused by the increased delivery frequency of the producer. The figure demonstrates that minimum inventory levels were still too high, leading to the conclusion that safety stock levels could be further reduced. This was particularly so for fastmoving articles, since one traditionally takes extra precautions with them (if a fast-moving article becomes out-of-stock, this has serious implications and all outlets will suffer).

Results of the pilot study for the main performance indicators in the retail DC and the CAOoutlet are summarised in Table 3. The improvements were mainly realised for fast-moving articles. The overall decrease in outlet out-of-stocks was estimated to be approximately $50 \%$. It should be noted here that in a pilot study orders of pilot-outlets are given high priority in the event of shortages (when possible, they receive 100\% delivery). Furthermore, inventories in the traditional outlet hardly decreased, since the outlet manager refused to order more frequently. For practical reasons he was reluctant to leave his traditional working practice, emphasising organisational consequences of changing SCM. The standard outlet revealed no changes in inventory, but did realise an increase in product freshness of approximately 3.8 days, as did the DC. Note that the product freshness delivered by the producer did not increase during the pilot period, since inventories there are turned over almost daily. Further, we can conclude that increasing the frequency of delivery to the CAO-outlet, together with the CAO-system, resulted in an additional increase of 1.2 days in product freshness.

From the case study it is clear that the main barriers to improving supply chain performance are the current information technology infrastructure and the reliance on decision makers. EDI and real-time control systems seem necessary on the one hand, and training and education on the other. Furthermore, the exact settings of the CAO-system (e.g., safety stock levels per day) greatly influence the results, as will be shown in the simulation study.

Table 3. Main results of the pilot study

Performance indicator Inventory level DC

Product freshness in DC Inventory level CAO-outlet

Product freshness for consumer at CAO-outlet
Consequence of pilot study

Decreased by $55 \%$ (to 1.9 days of stock) Increased by $(3.8$ days Decreased by $38 \%$ (to 4.2 days of stock) Increased by ( 5 days 
Table 4. Comparison of the results of the pilot study with the simulation study

\begin{tabular}{lll}
\hline Performance indicator & \multicolumn{1}{c}{ Pilot study } & Simulation model \\
\hline Inventory level DC & Decreased by $55 \%$ & Decreased by $41 \%$ \\
Inventory level CAO-outlet & Decreased by $38 \%$ & Decreased by $16 \%$ \\
Product freshness for consumer & Increased by \pm 5.0 days & Increased by \pm 3.7 days \\
\hline
\end{tabular}

\subsection{Model validation}

By comparing the results of the pilot study with the simulation results of the equivalent scenario, the outcomes of the simulation model can be justified. This was complicated by some factors. First of all, the CAO-system in the outlet was very difficult to model, just as the ordering policy used by the DC in the traditional situation. In practice, peaks in demand are smoothed by manual interference in the CAO-system (eliminating demand distortions). Secondly, the simulation model was fed with 20 weeks of sales data which showed more demand variability than sales data during the six weeks of the pilot study. Finally, in the model, inventory levels are calibrated to $100 \%$ delivery performance, which (virtually) increases inventories. Especially the elimination of final out-of-stocks requires an increase in inventory (c.f. Cachon and Fisher, 1996). This means that in the simulation study two "optimised" scenarios (both $0 \%$ out-ofstock) are compared, while in practice a "nearly optimised" situation $( \pm 2.5 \%$ out-of-stock in retail outlets) is compared with a situation with more slack ( $\pm 5 \%$ out-of-stock; mainly due to write-offs caused by high inventory levels). Hence, we found that the model showed fewer benefits to be obtained than were realised in practice (see Table 4).

Although the outcomes did not match exactly because of the reasons given, the working group concluded that the model did predict probable trends and order of magnitude of potential benefits to be obtained in different scenarios. Mainly because all participants had taken part in the development process of the simulation model and were fully aware of all underlying assumptions.

\subsection{Simulation and evaluation of scenarios}

In the simulation study we quantified consequences of different scenarios with respect to relevant performance indicators for 12 selected representative products, given 20 weeks of consumer demand at retail outlets (in which promotions were eliminated) and the cost of all individual activities per unit product. Note, that these settings can (and will!) be different for other supply chains. Twenty weeks of demand were sufficient for the model to arrive at an almost steady-state situation, which provides good estimates of the benefits to be obtained. Total chain costs are calculated by extrapolating these results to the total product assortment.

When the producer's lead time is decreased to one day, inventories decrease by $13 \%$ and a 0.7 day increase of product freshness in the DC is obtained. In Fig. 6 results are presented of

Results Retail DC

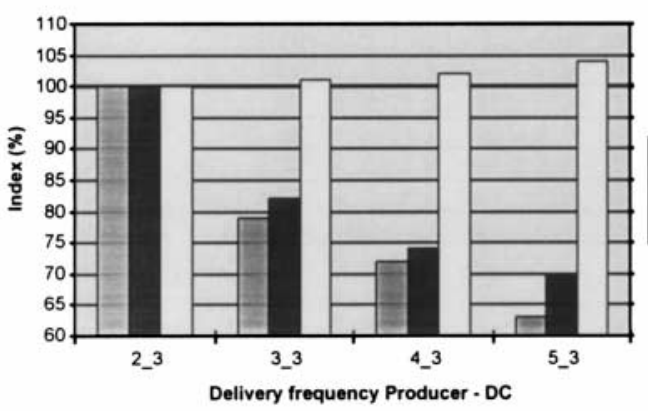

Results CAO-outlet

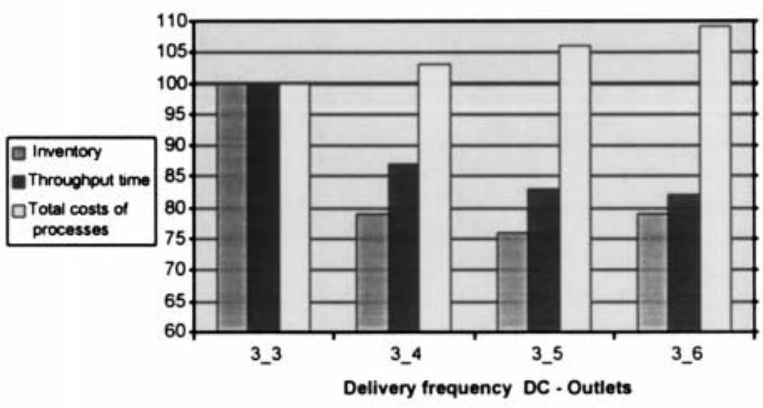

Fig. 6. Changes effected by altered delivery frequencies in simulation study (key: 2 _ 3 represents a delivery frequency of two times per week from producer to DC and a frequency of 3 times per week from DC to outlets). 
scenarios in which the delivery frequency is increased between all three sections, and the lead time in all scenarios is set at one day. To compare average inventory levels and throughput times of different scenarios, the simulation model is tuned to a delivery performance of $100 \%$ (a trade-off between stock-outs and write-offs while minimising inventory levels). It is interesting to note, however, that at lower delivery frequencies, it is not possible to set safety stock levels at which no out-of-stocks and no write-offs occur. If stocks are too high, write-offs are unavoidable. On the other hand, if stocks are too low, out-of-stock occur. Costs include stock holding costs and the costs of all logistical and administrative processes.

When the delivery frequency of the producer is increased to three times per week (left figure), DC inventory levels decrease by $21 \%$ and throughput times by $18 \%$ whereas total chain costs only rise $1 \%$ (due to higher picking and transportation costs). When the delivery frequency of the DC (right figure) is increased to four times per week, main benefits are realised; outlet inventory decreases by $21 \%$, throughput times decreases by $13 \%$, and total chain costs rise $3 \%$ (despite the decrease of inventory). Fast-moving articles reveal significantly better results than slow moving articles. Further increasing the delivery frequency seems to be practically useless, since the current distribution unit load (which equals the minimum ordering batch size and on average contains 12 products) restricts better results; the turnover of most products is only three or four unit loads per week. Furthermore, implementing a CAO-system further reduces inventories, if the right parameters concerning the validation of historical POS-data are chosen. Simulation shows that a relative performance improvement may be achieved to the standard scenario of $10 \%$ to $20 \%$. If the distribution unit load is set at one individual consumer product (batch size one), higher delivery frequencies become more beneficial. Here, simulation shows that these settings may result in $26 \%$ to $38 \%$ additional improvements in inventory levels and product freshness, compared to current unit loads. However, costs (especially order picking costs) may rise significantly $( \pm 23 \%)$.

\subsection{Evaluation of the case study}

Based on the results of the case study we conclude that reduction of uncertainties may improve service levels significantly, although current supply chain configurations restrict possible benefits. Comparable trends in results were obtained in a pilot project and with simulation studies, thereby validating the trends predicted by the simulation model. Which scenario a chain should choose depends on the trade-off between service levels and total chain costs. As stated before, product freshness can be seen as an order winner and reduction of throughput times is therefore very important. On the other hand, not all possible benefits are taken into account in the simulation model: inventory reduction creates additional shelf space, which can be used for assortment expansions; fewer out-of-stocks results in higher sales; and higher product freshness will improve customer service. Analysis showed that these additional benefits easily compensate for chain cost increases. To realise these improvements in practice, some operational restrictions have to be overcome. Note that during the pilot study, EDI and dynamic inventory control were simulated, but proved to be essential in obtaining the benefits. In addition, the settings of the CAO-system determined the extent to which improvements could be made. Information Technology, as well as to training and education of decision makers, is therefore a necessary condition (an enabling technology) to capitalise on the benefits of Supply Chain Management.

\section{DISCUSSION}

In practice there is a continuous need to redesign chain processes in order to better satisfy consumer demand and improve efficiency of these processes. Generating and evaluating alternative chain designs, scenarios as we have called them in this paper, cannot all be tested and evaluated in practice due to costs and risks involved. As a consequence there is a clear need for a modelling approach and a simulation model that supports decision makers to generate and evaluate decision alternatives. In our research so far we have been involved in redesigning two supply chains for (chilled) fresh products where we developed and used our modelling approach and 
simulation model successfully in practice. However, many questions from both a theoretical and a practical point of view have not been answered adequately. Part of these questions are addressed in our current research or will be addressed in the near future. In this context, we may mention questions relating to the theoretical relationship between sources of uncertainty that we identified, further validation of the simulation model as a prescriptive model, the sensitivity and robustness of the model, etc.

In this paper we have attempted to show that the reduction or elimination of uncertainties in supply chain decision processes may significantly improve supply chain performance. For the most part, this is because the control problem becomes more manageable. Next to inherent uncertainties, three main clusters of sources of uncertainty have been identified which restrict operational performances (order forecast horizons, input data, and administrative and decision policies). For each of the sources of uncertainty, principles for improving the performance were introduced. Although some of these improvement principles are also applicable in the context of an individual organisation (especially principles concerning decision rules), most benefits may be achieved when these are co-ordinated with supply chain partners. However, we can conclude that an organisation should preferably start SCM-activities in conjunction with optimising its internal control design. Our case study was conducted within food supply chains, but we feel that results may apply to other supply chains as well, although other performance indicators might be important. The exact benefits to be obtained are highly dependent on the characteristics of the supply chain and the objectives of participating companies.

\section{REFERENCES}

Axsäter, S. (1993) Continuous review policies for multi-level inventory systems with stochastic demand. In Logistics of Production and Inventory (Vol. 4), eds. S. Graves, A. Rinnooy Kan and P. Zipkin. Amsterdam: Elsevier.

van Beek, P. (1981) Modelling and analysis of a multi-echelon inventory system. European Journal of Operational Research 6, 380-385.

Beulens, A. J. M. (1992) Information technology and society; intriguing integration. Inaugural speech, Wageningen Agricultural University.

Bourland, K., Powell, S. and Pyke, D. F. (1996) Exploiting timely demand information to reduce inventories. European Journal of Operational Research 92 (2), 239-253.

Braithway, A. (1993) Logistic systems or customer focused organisation; which comes first? Logistics Information Management 6 (4), 26-37.

Cachon, G. P. (1995) Exact evaluation of batch-ordering policies in two-echelon supply chains with periodic review. Furqua School of Business, Working paper.

Cachon, G. P. and Fisher, M. (1996) Campbell soup's continuous replenishment program: evaluation and enhanced inventory decision rules. Furqua School of Business, Working paper.

Cachon, G. P. and Fisher, M. (1997) Supply chain inventory management and the value of shared information. Furqua School of Business, Working paper.

Chen, F. and Zheng, Y. S. (1995) One-warehouse multi-retailer systems with centralized stock information. Operations Research 45, 275-287.

van der Duyn Schouten, F. A., van Eijs, M. J. G. and Heuts, R. M. J. (1994) The value of supplier information to improve management of a retailer's inventory. Decision Science 25 (1), 1-14.

Ellram, L. M. (1991) Supply chain management; the industrial organisation perspective. International Journal of Physical Distribution and Logistics Management 21 (1), 13-22.

Fearne, A. (1996) Editorial note. Supply Chain Management 1 (1), 3-4.

Forrester, J. W. (1961) Industrial Dynamics. MIT Press, Cambridge, Massachusetts.

Harland, C. (1995) The dynamics of customer dissatisfaction in supply chains. International Journal of Production Planning and Control 6 (3), 209-217.

Hill, T. (1993) Manufacturing strategy: the strategic management of the manufacturing function. London: MacMillan Press.

Iyer, A. V. and Bergen, M. E. (1997) Quick response in manufacturer-retailer channels. Management Science 43 (4), $559-$ 570 .

Jones, T. C. and Riley, D. W. (1985) Using inventory for competitive advantage through supply chain management. International Journal of Physical Distribution and Materials Management 15 (5), 16-26.

Kreuwels, C. M. A. (1994) External logistical integration and EDI: to multi-level supply control between supplier and buyer. Ph.D. Dissertation, Eindhoven University of Technology, The Netherlands (in Dutch).

Kurt Salmon Associates (1993) Efficient Consumer Response; enhancing consumer value in the grocery industry. Washington D.C.: Food Marketing Institute.

Lee, H. L., Padmanabhan, V. and Whang, S. (1997) Information distortion in a supply chain: the bullwhip effect. Management Science $\mathbf{4 3}$ (4), 546-558.

Lewis, J. C. and Naim, M. M. (1995) Benchmarking of aftermarket supply chains. International Journal of Production Planning and Control 6 (3), 258-269.

McGuffog, T. (1997) The obligation to keep value chain management simple and standard. Supply Chain Management 2 (4), 124-133. 
Moinzadeh, K. and Aggarwal, P. K. (1996) An information based multi-echelon inventory system with emergency orders. Operations Research, to appear.

Scott, S. and Westbrook, R. (1991) New strategic tools for supply chain management. International Journal of Physical Distribution and Logistics Management 21 (1), 23-33.

Silver, E. A. (1991) Modelling in support of continuous improvements towards achieving world class operations. In: Perspectives in Operations Management, ed. R. K. Sarin. Kluwer.

Stalk, G. and Hout, T. M. (1990) Competing against time; how time-based competition is reshaping global markets. New York: Free Press.

Stevens, G. C. (1989) Integrating the supply chain. International Journal of Physical Distribution and Materials Management 19 (8), 3-8.

Svoronos, A. and Zipkin, P. (1988) Estimating the performance of multi-level inventory systems. Operations Research 36 (1), 57-72.

Thiery, M., Salomon, M., Van Nunen, J. and Van Wassenhove, L. (1995) Strategic issues in product recovery management. California Management Review 37 (2), 114-135.

Towill, D. R. (1996) Time compression and supply chain management — a guided tour. Supply Chain Management 1 (1), $15-27$.

Verrijdt, J. H. C. M. (1997) Design and control of service part distribution systems. Ph.D. Dissertation, Eindhoven University of Technology, The Netherlands.

van der Vorst, J. G. A. J., Beulens, A. J. M., van Beek, P. (1998) Redesigning food supply chains: an integral logistical approach. In: Proceedings of the 3rd International Conference on Chain Management in Agri-and Food Business, eds. G. W. Ziggers and J. H. Trienekens, pp. 77-90. Wageningen. 